
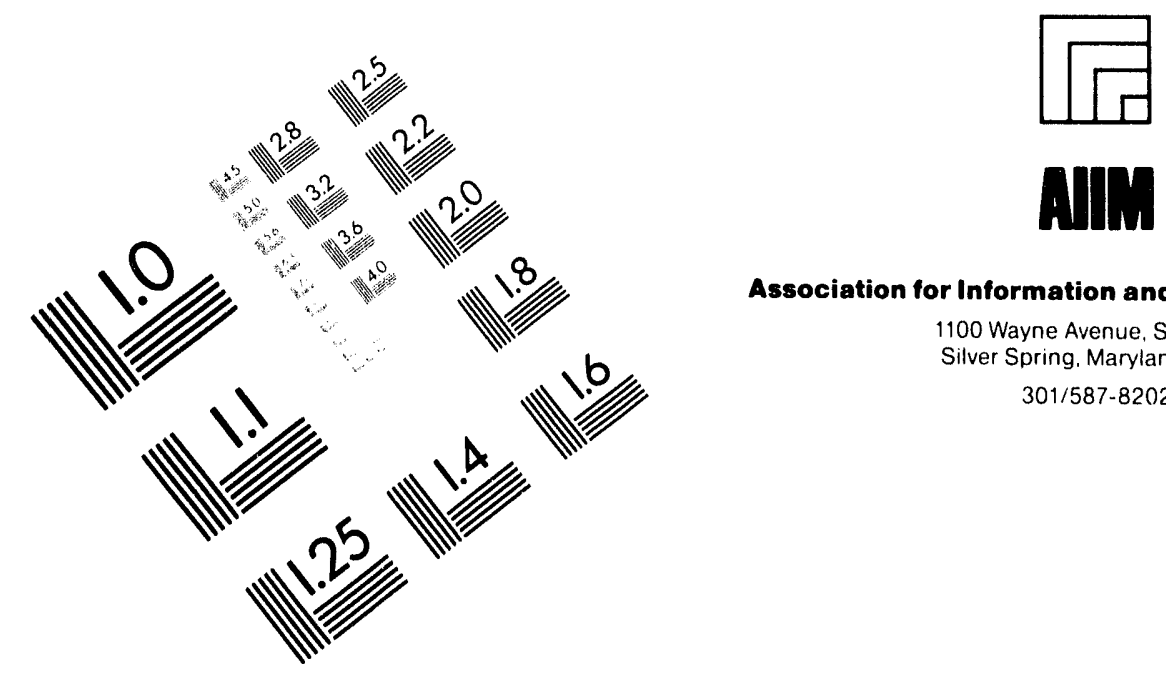

Association for Information and Image Management

1100 Wayne Avenue, Suite 1100

Silver Spring. Maryland 20910

$301 / 587-8202$

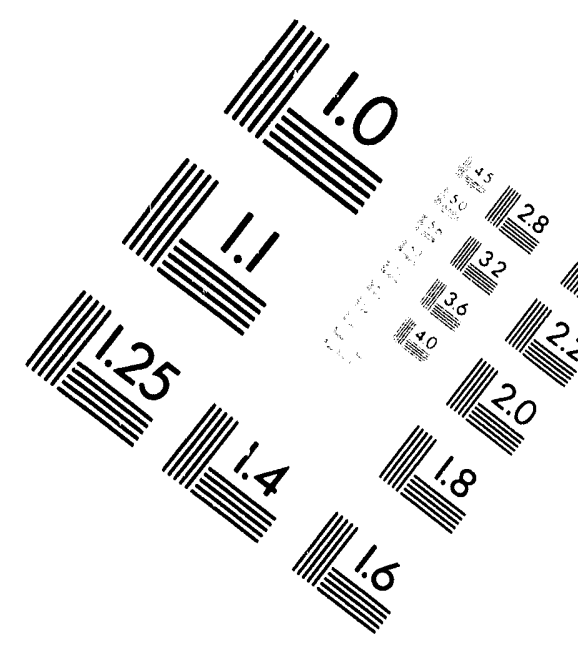

\title{
Centimeter
}

$\begin{array}{llllllllllllllll}1 & 2 & 3 & 4 & 5 & 6 & 7 & 8 & 9 & 10 & 11 & 12 & 13 & 14 & 15 & \mathrm{~mm}\end{array}$

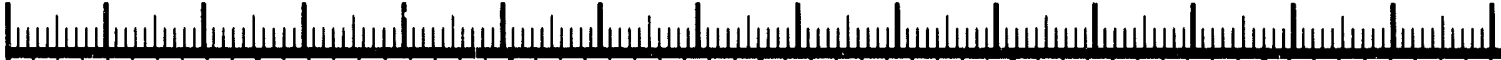
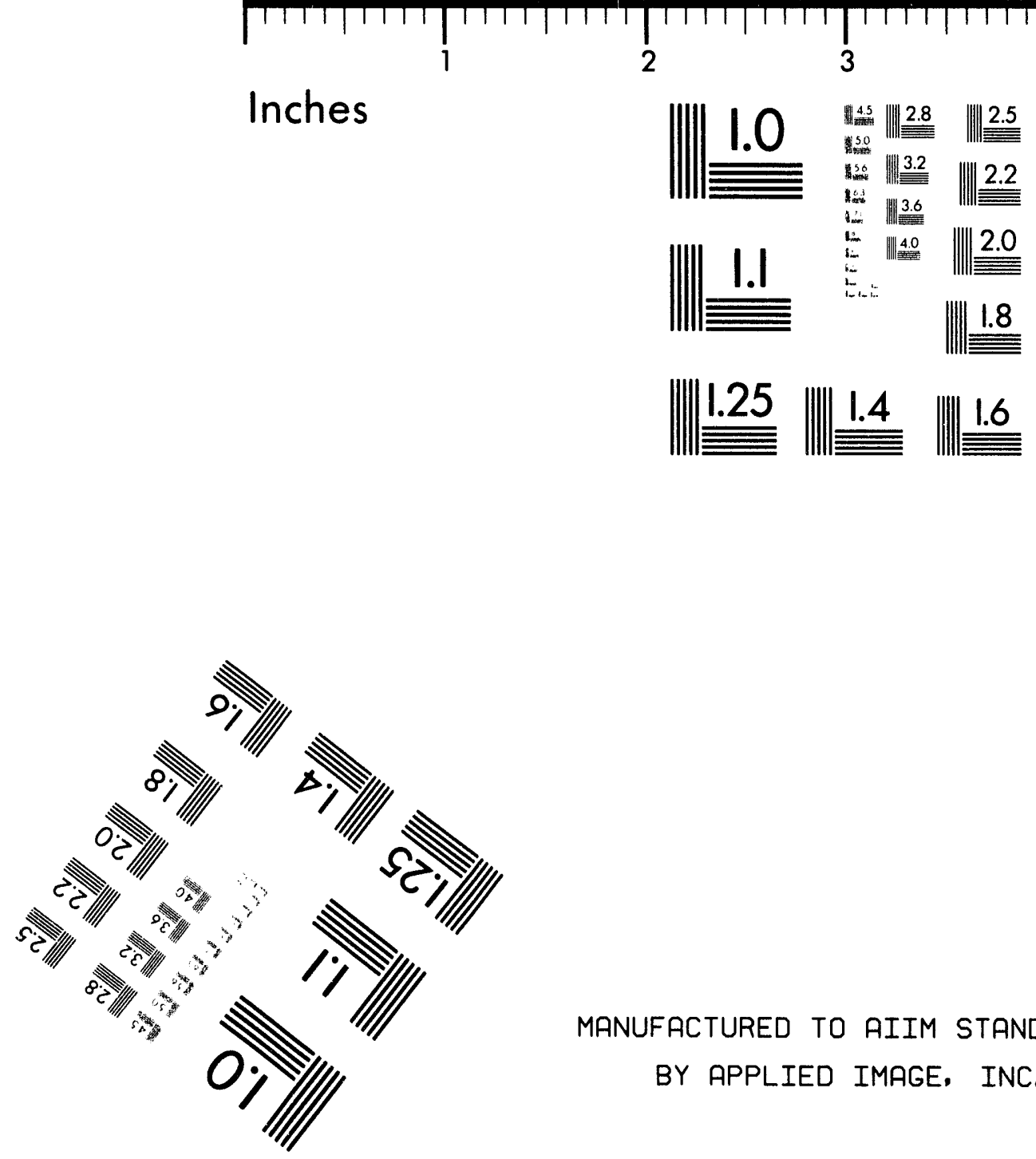

MANUFACTURED TO AIIM STANDARDS

BY APPLIED IMAGE, INC.

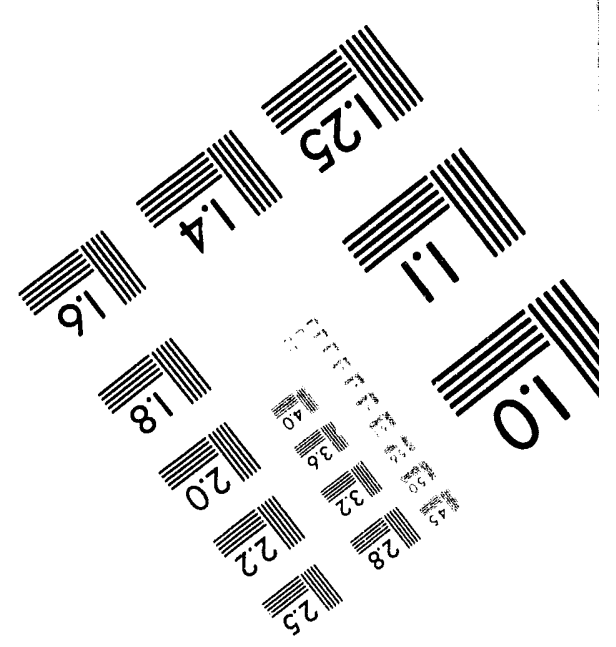



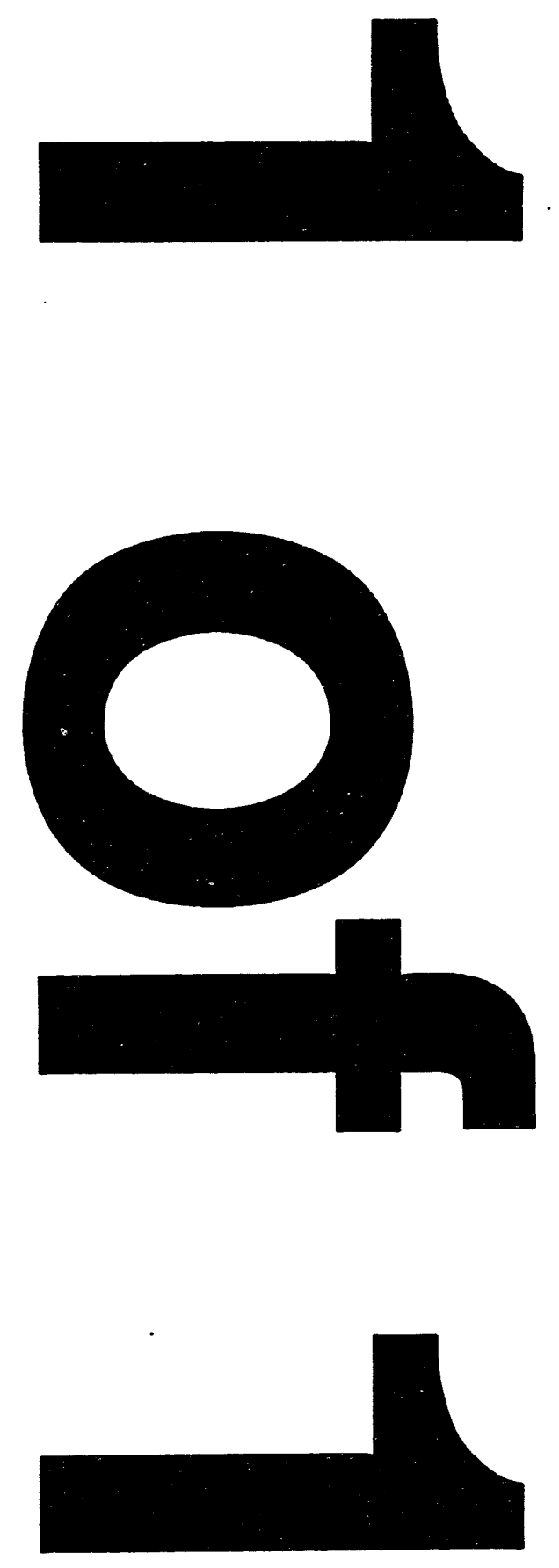


\title{
$10 / 129495$ \\ SANDIA REPORT
}

SAND94-0383 $\cdot$ UC-706

Unlimited Release

Printed May 1994

\section{Laser Drilling of Printed Wiring Boards: Final Report of Work Sponsored by Sandia LDRD Program}

\author{
James S. Arzigian
}

\author{
Prepared by \\ Bandla National Laboratoriee \\ Albuquerque, Now Moxico 87185 and Livermore, Callfornia 94550 \\ for the United Statee Dopartment of Enoroy \\ undor Contract DE-ACO4-OAAL8S000
}

Approved for public release; distribution is unlimited. 
Issued by Sandia National Laboratories, operated for the United States Department of Energy by Sandia Corporation.

NOTICE: This report was prepared as an account of work sponsored by an agency of the United States Government. Neither the United States Government nor any agency thereof, nor any of their employees, nor any of their contractors, subcontractors, or their employees, makes any warranty, express or implied, or assumes any legal liability or responsibility for the accuracy, completeness, or usefulness of any information, apparatus, product, or process disclosed, or represents that its use would not infringe privately owned rights. Reference herein to any specific commercial product, process, or service by trade name, trademark, manufacturer, or otherwise, does not necessarily constitute or imply its endorsement, recommendation, or favoring by the United States Government, any agency thereof or any of their contractors or subcontractors. The views and opinions expressed herein do not necessarily state or reflect those of the United States Government, any agency thereof or any of their contractors.

Printed in the United States of America. This report has been reproduced directly from the best available copy.

Available to DOE and DOE contractors from Office of Scientific and Technical Information

PO Box 62

Oak Ridge, TN 37831

Prices available from (615) 576-8401, FTS 626-8401

Available to the public from

National Technical Information Service

US Department of Commerce

5285 Port Royal Rd

Springfield, VA 22161

NTIS price codes

Printed copy: A03

Microfiche copy: A01 
SAND94-0383

Distribution

Unlimited Release

Category UC-706

Printed May 1994

\title{
LASER DRILLING OF PRINTED WIRING BOARDS: FINAL REPORT OF WORK SPONSORED BY SANDIA LDRD PROGRAM
}

\author{
James S. Arzigian \\ Electronic Processing Department \\ Sandia National Laboratories \\ Albuquerque, NM 87185-0957
}

\begin{abstract}
Traditionally, electrical connections between layers of a printed wiring board are formed by mechanically drilling holes through all layers and then plating the resulting structure to provide electrical connections between the layers. The mechanical drilling process is very capital- and labor-intensive and is often a bottleneck in board production. The goal of this program was the development of laser drilling as an alternative to mechanical drilling. Cost advantages and the ability to produce smaller holes were both of interest. Although it had initially been intended to develop all processes at Sandia, suitable emerging processes and materials were identified in industry during the course of the work. Because of these industry efforts, it was decided to terminate the LDRD efforts after the first year of work and to pursuc collaborative development efforts with industrial partners. A laser drilling facility is currently being developed at Sandia to pursue this work further.
\end{abstract}

\section{MASTER}






\section{OVERVIEW OF THE GOALS OF THE LDRD LASER DRILLING PROGRAM}

Electrical connections between layers of a printed circuit board have traditionally been accomplished through the use of drilled plated through holes in the board. Mechanical, numerically controlled drills are the standard tool for this work in current industrial practice. Wet chemical plating on the drilled hole walls is used to provide electrical conductivity between layers. An advanced technology board today might contain 30-40 thousand holes with diameters down to 8 mils. A single drilling machine may be capable of producing up to 5 holes/second. Such a machine costs from $\$ 200 \mathrm{~K}$ $\$ 750 \mathrm{~K}$. A large printed wiring board production facility will have as many as forty or fifty such machines. The drilling operation is often the limiting factor in board throughput. One goal of the present program was a reduction in the required capital expenditures for a drilling operation.

In the past, there have been periodic shortages of small diameter drills. As might be expected, the small diameter drills are more expensive than larger drills. It was a shortage of drills and an interest from computer makers to use smaller diameter holes in their printed circuit boards which initially prompted consideration by Sandia of work in laser drilling. There had been limited uses of lasers in board fabrication in the past, but there was no acceptance by general industry of any kind of laser drilling technology. We hoped to develop a technique which would be cost competitive with mechanical systems and also be able to avoid the high marginal costs associated with mechanical drills.

Drilling small diameter $(8 \mathrm{mil})$ holes requires spindle speeds in excess of 100000 $\mathrm{rpm}$. Small drills have a fairly limited useful lifetime, because even a small amount of drill damage can lead to instability and drill breakage. Should a drill break in a hole, it may be necessary to scrap the entire board. Since drilling comes ncar the end of the board fabrication process, such scrap is very expensive. While hole diameters below 8 mils would be useful for advanced, high-density designs, drilling such holes mechanically presents formidable challenges. Precise alignment of the drill is crucial; large hole aspect ratios must be avoided to eliminate problems with drill wander and breakage; and these bits (down to human hair diameter) are significantly more expensive than larger ones. The program goals were to be able to utilize the small beam size of a laser to produce small holes and to use the laser optical control system to provide precision alignment.

Since there is a substantial base of printed wiring board fabrication equipment already present, one of the program goals was to introduce a new hole fabrication technique which had as small an impact as possible on the rest of the board production processes. A technique which required all new production equipment would be much less likely to be accepted by industry. In addition, it was desirable that board designs not have to be changed because of the new cutting technique. This would allow laser cutting to be used interchangeably with mechanical methods for some board designs. 
Buried vias are holes only connecting some inner layers of a circuit board. Blind vias are holes originating at one surface of a board and going only part way through the board. Both buried and blind vias are attractive in the design of densely packed boards. They improve board real estate utilization and can sometimes significantly increase electrical performance. These vias will be essential to such products as Multichip modules fabricated with laminated materials. Laser cutting has the potential to produce such vias in a simpler and more controlled fashion than mechanical drilling.

The reliability of a printed wiring board is directly related to the reliability of the plated through holes. Extensive testing has been done over the years to insure that the electrical path in a plated through hole remains intact through a variety of mechanical and thermal shocks. Any replacement of current technology would need to demonstrate at least as good reliability data.

Besides improvements in current products, laser drilling has the potential to provide a stepping stone to new packaging techniques. Such techniques include the various forms of Multichip modules, bare silicon chips mounted on board material, laser tuning and repair of circuitry, and the placement of vias in the solder pads used to attach parts to the board. The small hole sizes and accurate placement possible with a laser make many of these techniques possible in printed circuit board laminated structures. The competing technologies utilize various forms of ceramic substrates. Such substrates are up to ten times more expensive than printed wiring board materials. It is quite possible that a laser drilling system would also be useful for other applications such as optical inspection and measurement and film alignment for photolithography.

\section{MATERIALS AND EQUIPMENT ISSUES}

It was hoped that whatever process was developed for laser drilling would change the rest of the printed wiring board fabrication scheme as little as possible. This would aid in eventual implementation in industry of a general purpose drilling method. For this reason, it would have been desirable to utilize FR4, a standard board material used for a large majority of boards made for general industrial and consumer applications. FR4 obtains its mechanical strength from imbedded mats of woven glass fabric. This fabric makes a material with discernible non-uniformities over the scale of a small drilled hole. In the process of mechanical drilling, glass fibers are exposed in the resulting hole which are then either chemically or physically removed before plating. Many laser cutting methods would not attack this glass fabric or might leave residue not removable with standard techniques. The small holes we hoped to obtain would make it difficult to use some standard chemical and physical removal methods. Alternative materials werc examined as possible substitutes for FR4 in laser drilling. It was during the course of this search for alternative materials that we became aware of industry efforts directed at laser drilling. The scope and impact of this work on this program will now be described.

Norplex-Oak, a manufacturer of a wide variety of laminate materials developed thermount, an alternative laminate with a non-woven reinforcement. The resulting 
material is smoother and more homogeneous than standard materials but lacks the requisite mechanical strength. However, a laminate made with inner layers of FR4 and outer layers of thermount is a suitable board construction. In this case, blind vias would be drilled through outer layers of thermount only, and inner layers, where dense via packing is much less critical could receive standard board drilling. An issue to be resolved in ongoing research is whether small vias can be drilled through such a combination of laminate materials with a laser and whether FR4 on its own might be used for very small holes with suitable process modifications.

During the course of examining materials for laser drilling, we found that an industrial concern, MicroPak Laboratories, was preparing to introduce a laser drilling process based on blind drilling of thermount outer layers. Since it appeared that this process could potentially meet the needs we had outlined for our program, we conducted an in-depth examination of their methods and results. The MicroPak method utilizes an etched hole in the copper foil covering laminate material as a mask for a laser drilling operation. A laser beam is scanned across a board and pulsed on a location where a hole is desired. Copper around the top of the hole and copper at the base of the hole limit the extent of the laser cut. Subsequent cleaning and plating operations produce a plated through hole similar to those produced by a mechanical drill, with the exception of a taper in hole diameter with depth.

A detailed examination of the MicroPak processes convinced us to produce some boards made with it and determine yield and reliability data. If satisfactory results could be obtained with this process, then further work on alternative cutting methods would not be necessary at Sandia. The following section describes the fabrication and testing of a lot of boards made with the MicroPak method. Success in this board fabrication caused us to terminate work on the LDRD after one year of effort. It appeared that collaboration with industry to improve processes would be a better approach to the problem.

\section{TEST BOARD FABRICATION AND TEST RESULTS}

A test board containing over 5000 vias was utilized to evaluate the MicroPak process. The board has arrays of vias cut in pads such as would be used to mount highdensity surface mount packages. Figures 1 and 2 show the top and bottom layers of the board. The vias are daisy chained together in groups to facilitate electrical testing of the finished product. The two main testing issues are the process yield of good vias and the reliability of the vias through thermal and mechanical stresses. Two hundred boards were manufactured using the MicroPak laser drilling and plating techniques. Two hundred more boards were laser drilled and not plated. The laser drilling was done at the Laser Machining Center, Mountain View, California, through a contract with MicroPak, and plating at a MicroPak collaborating company. The two hundred unplated boards will be used at Sandia to further study plating methods on laser drilled boards. 
All two hundred boards that were both drilled and plated were completely electrically tested to determine process yield. There were blind vias on both the tops (A side) and bottoms (F side) of these boards. Tables 1 and 2 show the results of these tests.

\begin{tabular}{|l|r|}
\hline \multicolumn{1}{|l|}{ SIDE A } & NUMBER OF BOARDS \\
\hline NUMBER OF DEFECTS & 168 \\
\hline 0 & 14 \\
\hline 1 & 3 \\
\hline 2 & 4 \\
\hline 3 & 3 \\
\hline 4 & 3 \\
\hline 5 & 1 \\
\hline 6 & 1 \\
\hline 8 & 2 \\
\hline 9 & 1 \\
\hline 15 & \\
\hline
\end{tabular}

TABLE 1

\begin{tabular}{|l|r|}
\hline SIDE B & \multicolumn{1}{|l|}{} \\
\hline NUMBER OF DEFECTS & NUMBER OF BOARDS \\
\hline 0 & 174 \\
\hline 1 & 10 \\
\hline 2 & 3 \\
\hline 3 & 6 \\
\hline 4 & 1 \\
\hline 5 & 1 \\
\hline 6 & 1 \\
\hline 9 & 1 \\
\hline 15 & 1 \\
\hline 20 & 1 \\
\hline 37 & 1 \\
\hline
\end{tabular}

TABLE 2

If the three worst boards on each side are eliminated, the remaining boards contain approximately 1168000 holes produced with a production defect rate of about $110 \mathrm{ppm}$. Compared to the standard mechanical drilling done in the Sandia printed circuit facility, this is a very high yield. These boards are now being subjected to a battery of thermal and mechanical stresses to evaluate long-term reliability. 


\section{SUMMARY AND CONCLUSION}

The effort to develop a laser drilling system for printed wiring boards at Sandia lead to consideration of emerging industry capabilities. Sandia is now in the process of purchasing equipment to pursue laser drilling in house. Preliminary results with outside produced product look very promising. 


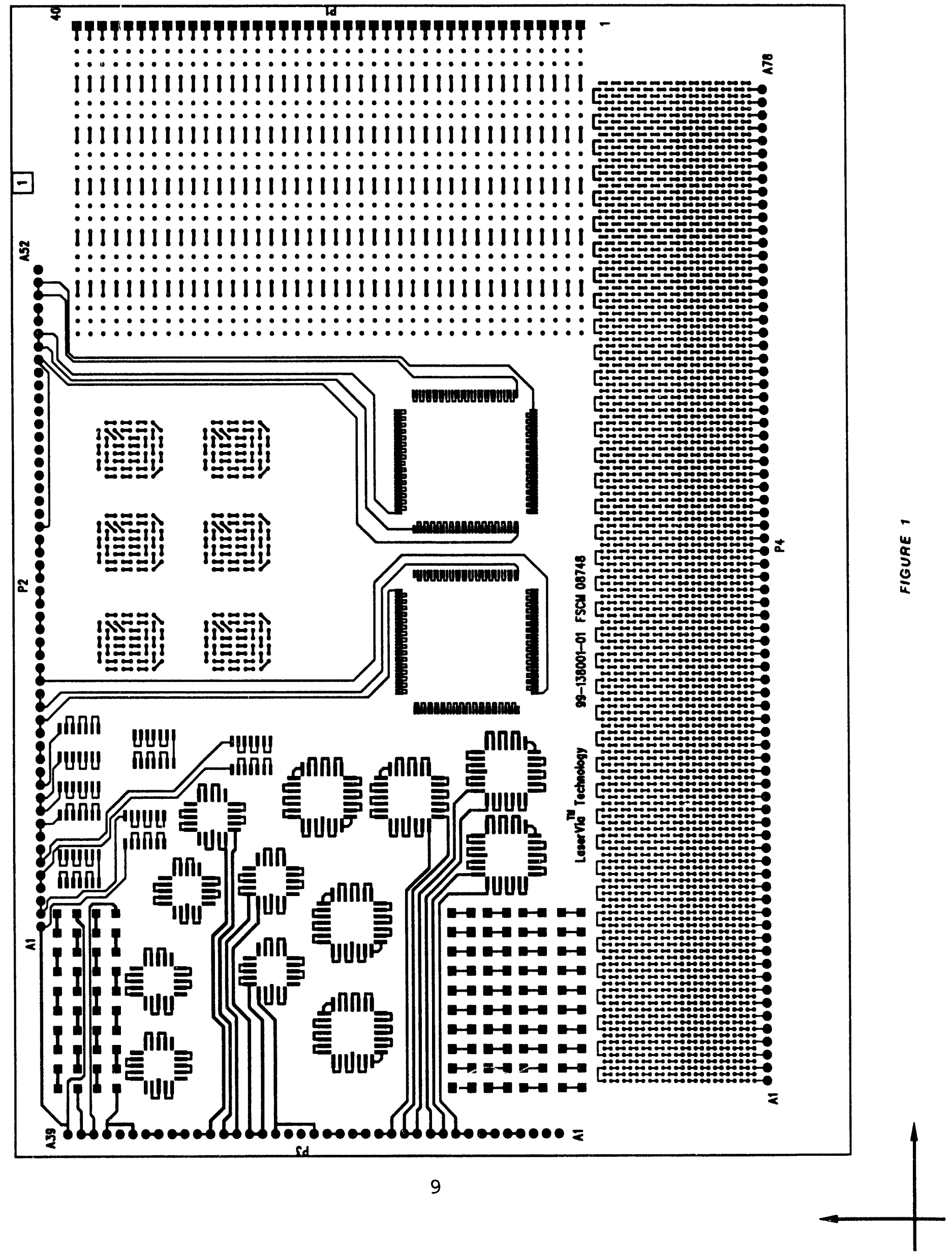




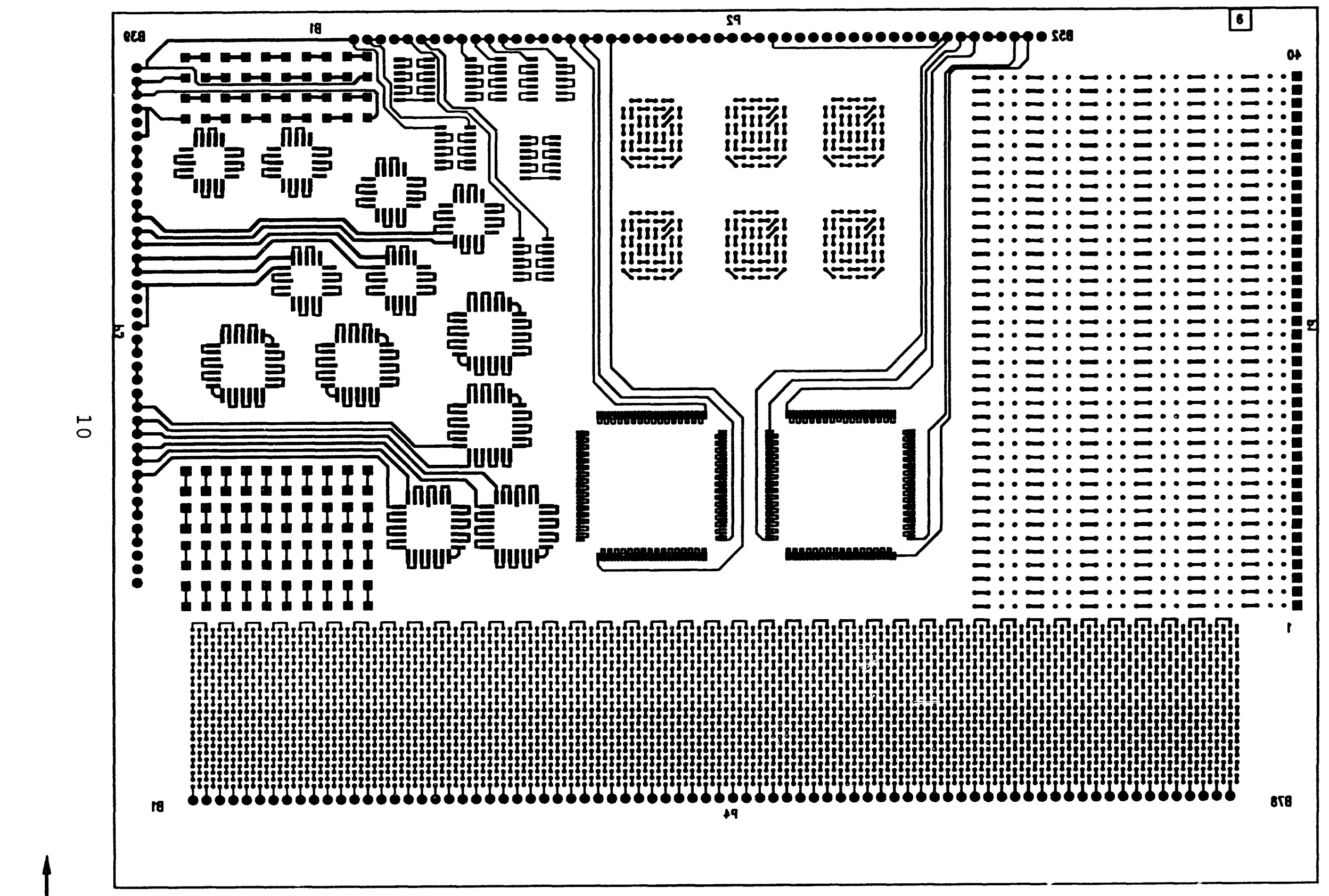


Distribution:

Larry Burgess, Micropak Labs 228 Southwest Forest Cove Road West Linn, OR 87068-9401

$\begin{array}{lll}\text { MS-0320 } & \text { C. M. Meyers } & 1011 \\ \text { MS-0320 } & \text { P. L. Mattern } & 1010 \\ \text { MS-0957 } & \text { G. L. Dybwad } & 2411 \\ \text { MS-0957 } & \text { S. E. Garrett } & 2411 \\ \text { MS-0957 } & \text { W. Worobey } & 2411 \\ \text { MS-0957 } & \text { T. A. Estes } & 2411 \\ \text { MS-0957 } & \text { N. J. Schwentor } & 2411-1 \\ \text { MS-0957 } & \text { G. L. Cessac } & 2411 \\ \text { MS-0957 } & \text { J. S. Arzigian } & 2411(10) \\ \text { MS-9018 } & \text { Central Technical Files } & 8523-2 \\ \text { MS-0899 } & \text { Technical Library } & 7141(5) \\ \text { MS-0619 } & \text { Technical Publications } & 7151 \\ \text { MS-0100 } & \text { Document Processing } & 7613-2(10) \\ & \text { for DOE/OSTI } & \end{array}$



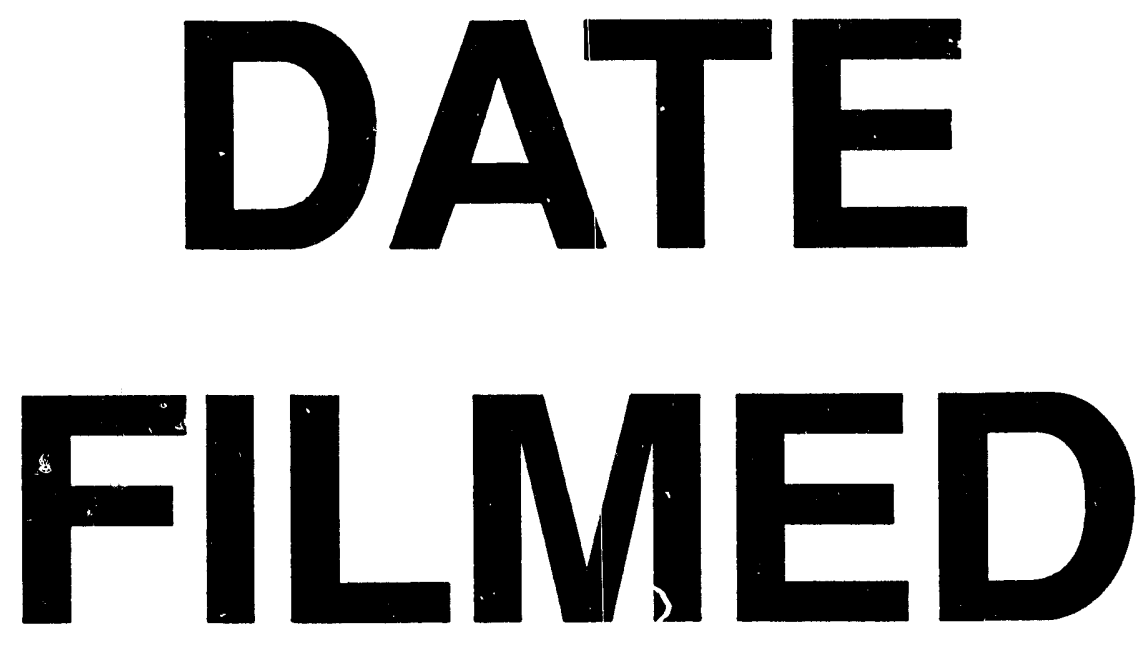

$6 / 23 / 94$
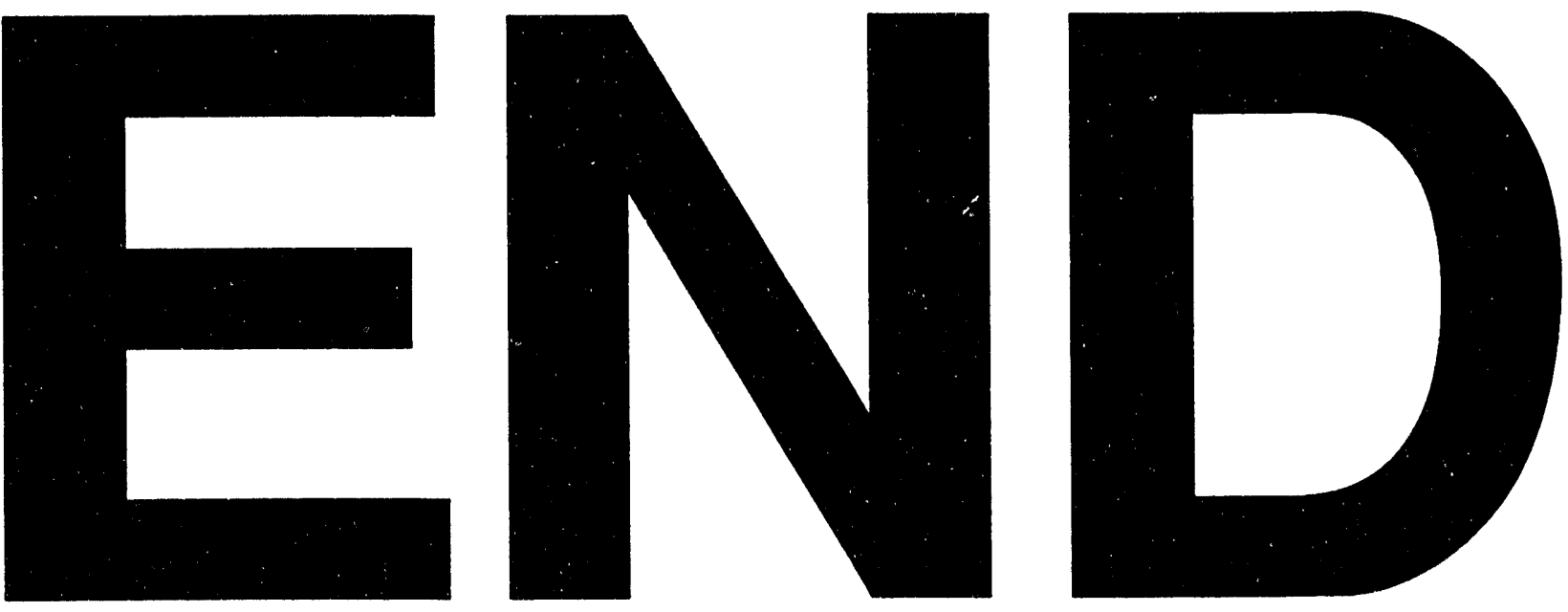
